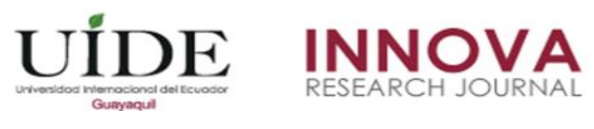

INNOVA Research Journal, ISSN 2477-9024

(Octubre, 2017). Vol. 2, No.10 pp. 178-193

DOI: https://doi.org/10.33890/innova.v2.n10.2017.383

URL: http://revistas.uide.edu.ec/index.php/innova/index

Correo: innova@uide.edu.ec

\title{
Estudio sobre el incremento de créditos en las instituciones financieras privadas en el Ecuador
}

\section{Study on the increase of credits in private financial institutions in Ecuador}

Ing. Juan Carlos Muñoz Briones, M.Sc.

Universidad Metropolitana, Ecuador

Lcda. Jessica Lalangui, M.Sc.

Universidad Metropolitana, Ecuador

Autor para correspondencia: jlibra_88@ hotmail.com

Fecha de recepción: 02 de Agosto de 2017 - Fecha de aceptación: 30 de Septiembre de 2017

Resumen

Las instituciones financieras juegan un rol muy importante en la economía nacional, siendo estas la fuente de desarrollo económico y de inversión, es por esto que la presente investigación muestra el nivel crediticio de las instituciones privadas en el último periodo de 4 años, la investigación tiene carácter descriptivo y analítico, siendo uno de sus resultados que el segmento comercial prioritario es el que representa la mayor parte del crédito otorgado $(45,79 \%)$, seguido por consumo prioritario con el $(29,16 \%)$, considerando que en el mismo lapso de tiempo ocurrieron diversos acontecimientos que alteraron el normal desarrollo económico de la nación.

Palabras clave: finanzas públicas; créditos; pib; riesgo; tasas de interés; apreciación

\begin{abstract}
Financial institutions play a very important role in the national economy, which is the source of economic and investment development. This is why the present research shows the credit level of private institutions in the last 4-year period. (45.79\%), followed by Priority consumption with $(29.16 \%)$, considering that in the same one a period of time occurred several events that altered the normal economic development of the nation.
\end{abstract}

Key words: public finance; credits; pib; risk; interest rates; appreciation 


\section{Introducción}

Una de las características de la economía ecuatoriana es su debilidad y su dependencia directa de estabilidad a factores externos como las divisas o el precio del barril de petróleo, las proyecciones con las cuales empezó el gobierno este año tuvieron grandes limitaciones debido al terremoto suscitado el 16 de abril del 2016 en la costa ecuatoriana. Tragedia que cobró la vida de decenas de compatriotas y dejó a la intemperie a miles de personas. (INEC, 2016). Ante lo cual el gobierno direccionó ayuda destinada labores de búsqueda y de cuidado y manutención de las víctimas.

Este motivo no es la causa de la recesión que atraviesa la economía ecuatoriana, pero si es uno de los factores que la acrecentó. Según proyecciones sobre la economía mundial realizadas por el Fondo Monetario Internacional (FMI) en su publicación de enero del 2017 apuntan a un repunte de la actividad económica en el 2017 y 2018, especialmente en las economías de mercados emergentes y en desarrollo. Sin embargo, existe una amplia dispersión de posibles desenlaces en torno a las proyecciones, dada la incertidumbre que rodea a la economía mundial.

El actual momento económico está caracterizado por incertidumbres generadas por los mercados debido a las políticas de los gobiernos contemporáneos enfocados en la apertura de mercados unos y en el proteccionismo otros, el caso Trump en Estados Unidos de Norteamérica.

El normal desenvolvimiento de crédito de los agentes económicos, el flujo natural de la economía que condiciona el marco de acción de los agentes y las diferentes políticas de crédito, control y seguimiento en cuanto a la intermediación financiera establecen el riesgo implícito en cada operación. Estos riesgos determinados a través del comportamiento de las variables como: el nivel de crédito, el índice de morosidad y el nivel de aprovisionamiento. (Asociación de Bancos Privados del Ecuador, 2016). Las mismas que están enfocadas en la evaluación del grado de respuesta de los entes otorgantes de crédito ante situaciones que puedan presentarse a los sujetos de crédito y en las actividades que se financian con la premisa de evitar a toda causa el deterioro de la situación financiera. Este artículo está enfocado en la realización de una breve síntesis del nivel crediticio por parte de la banca privada en el sistema financiero.

\section{Metodología}

El presente artículo está orientado a realizar una descripción de la situación crediticia en el Ecuador, estableciendo una sinergia entre el nivel de crédito otorgado por las Instituciones del Sistema Financiero privado reguladas por la Súper Intendencia de Bancos y Seguros y el impacto que ha tenido en la economía los shocks tanto internos como externos, los mismos que han repercutido en el detrimento del nivel de vida de los ecuatorianos.

Por lo que, se tomó como periodos de estudio desde el año 2014 hasta inicios del 2017 , con el fin de sustentar a través de fuentes oficiales de control. Para luego relacionar de acuerdo a evidencias de la Asociación de Bancos Privados del Ecuador la evolución crediticia en el país durante el último periodo de gobierno, a partir del otorgamiento de créditos de diferente clase y 
provincias de mayor proyección crediticia. Información que sustenta la polaridad en la democratización de las actividades crediticias en el contexto nacional.

\section{Resultados}

Como medidas para apoyar a los damnificados los bancos decidieron ajustar sus procesos operativos para destinar un lapso de 90 días de aplazamiento de cuotas de créditos a personas naturales e iniciar una etapa para reestructurar las operaciones para emprendimientos o empresas de la región. (Asociación de Bancos Privados del Ecuador, 2016).

Este plazo fue de análisis, debido a que permitió que cada institución se contacte directamente con sus clientes para el establecimiento de acuerdos de pago de las deudas contraídas, teniendo como premisa la consideración la nueva realidad de las personas afectadas. Luego de este análisis las instituciones financieras hicieron una evaluación de las nuevas solicitudes de crédito que se presentaron, ajustándolas a los parámetros que habían establecido para el caso. Si bien durante las semanas subsiguientes al terremoto las prioridades de los clientes fue restructurar deudas actuales en detrimento de la contratación de nuevas líneas.

Hasta marzo de 2016, la cartera bruta total entregada para las provincias de Manabí y Esmeraldas representó US\$866 millones de dólares, de la cual Manabí concentra la mayor parte con un total de US\$767 millones. Enfocándonos en esta provincia, vemos que el destino del crédito va en su mayoría al segmento comercial (US\$342 millones), seguido por consumo (US\$223 millones) y microcrédito (US\$120 millones). Es por esto que quedan evidentes los esfuerzos de varias entidades financieras de enfocarse en el área productiva, sin tener en consideración a la vivienda, reestructurando las líneas de crédito para las pequeñas empresas dentro del sector comercial.

Adicionalmente a las acciones emprendidas por el terremoto y aquellas que se tomarán más adelante, la banca tiene que seguir manejándose con el profesionalismo, la técnica y la prudencia que ha caracterizado al sistema, pues hay que recordar que existe una recesión económica en el resto del país que se suma a los efectos económicos negativos del terremoto. La compleja situación que genera un menor dinamismo económico se refleja en dos frentes:

1. Un nivel de captaciones del público que todavía no recupera niveles adecuados, pues si bien en los últimos cuatro meses se ha reversado ligeramente la tendencia de reducción experimentada en el año 2015, todavía, al no haber liquidez y dinamismo suficiente en la economía, los depósitos no crecen con mayor velocidad.

2. Por el lado de la cartera, se encuentra todavía poco dinamismo en la demanda de créditos. Los bancos enfrentan dificultad en ciertos sectores para encontrar clientes que sean sujetos de crédito y que además quieran tomarlo, pues existe incertidumbre económica y eso frena a los clientes que prefieren mantenerse cautos y no invertir o comprar. El otro fenómeno, también por el lado de la cartera, es que se sigue evidenciando un deterioro de la cartera vencida, es decir que la morosidad está creciendo por efecto de la recesión económica.

3. La estabilidad económica como se ve en (Comisión Económica para América Latina y el Caribe (CEPAL), 2015) depende de varios factores, entre otros como la estabilidad de las 
instituciones financieras que se encargan de captar dinero y colocar créditos. La banca, desde sus inicios en la economía ecuatoriana se fundamentó en la creación de riqueza, el desarrollo de la inversión y la acuñación de moneda, funcionalidad que ya no está presente en las actividades actuales de las instituciones financieras debido a la época dolarizada en la que vivimos. Uno de sus grandes objetivos es el de la capacidad de captar el ahorro y distribuirlo entre las empresas y las familias que demandan fondos prestables para financiar sus actividades económicas. Mediante este proceso, el sector bancario incentiva el crecimiento económico, sobre todo en países que no cuentan con fuentes alternativas de financiación como son los mercados de capitales desarrollados.

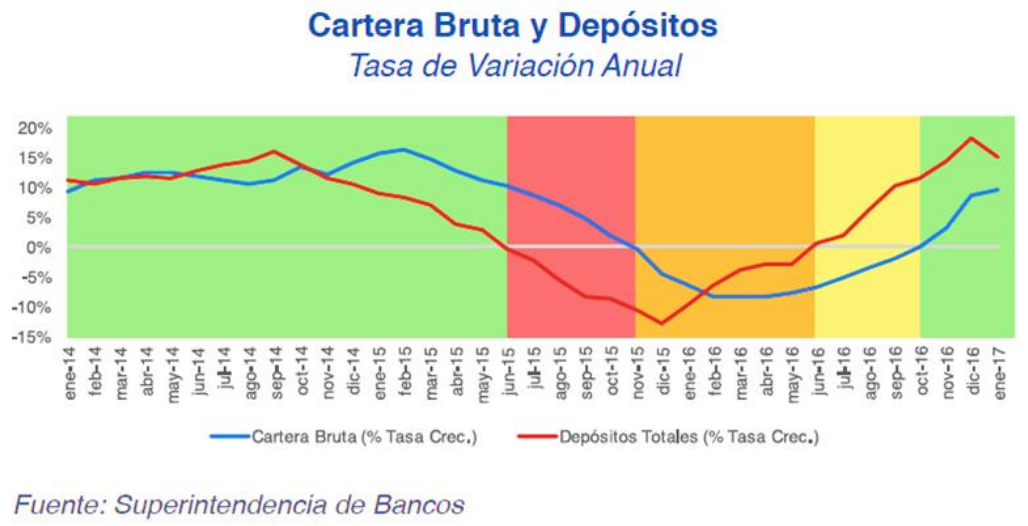

Ilustración 1: Cartera bruta y depósitos.

La economía cierra el año con una contracción, este resultado se debe principalmente a una débil demanda interna y a la caída de la inversión y del consumo. Asimismo, tanto la balanza comercial no petrolífera como la producción petrolífera han empeorado. (Asociación de Bancos del Ecuador, 2017) A esta situación han contribuido el reducido precio del petróleo y el coste de la recuperación del reciente terremoto. Por su parte, se observa una disminución de la inflación. Sin embargo, se está produciendo un deterioro de la calidad y cantidad del empleo, que está generando un mayor desempleo, afectando al nivel de consumo.

En los últimos tres años (2014 a 2016), la banca ha transitado por cuatro diferentes etapas en lo que respecta a la variación anual de depósitos y créditos. La primera fase, se refiere a un momento donde tanto las captaciones como las colocaciones experimentan un crecimiento positivo. La segunda está determinada por un menor crecimiento en la cartera de créditos, y una contracción de depósitos. La tercera etapa refleja un decrecimiento de los depósitos y créditos. Finalmente, la cuarta etapa se caracteriza por una variación positiva de los depósitos, mientras que la cartera de créditos permanece en contracción. (Asobanca, 2017).

\section{El sistema bancario latinoamericano}

Según la Federación Latinoamericana de Bancos el sistema bancario latinoamericano al mes de septiembre de 2016 experimentó una coyuntura acorde con la situación macroeconómica. Por un lado, el activo total creció un 14\% anual en términos nominales. La cartera de créditos se expandió a una tasa anual del 12,4\% y los depósitos a una tasa cercana al 10\%. Un breve ejercicio para mirar con detalle la coyuntura de la cartera crediticia se obtiene al descontar el 
efecto de las variaciones de los tipos de cambio, muy afectados por la coyuntura de volatilidad que se registra en los mercados financieros internacionales. En ese sentido, el resultado es que la tendencia de la cartera es decreciente. Al respecto, habría que decir que el peso relativo que tienen algunos de los grandes países afectados por momentos adversos de sus economías afecta el resultado. Sin embargo, la mayoría de países medianos y de menor tamaño dan cuenta de un resultado que se puede calificar de aceptable.

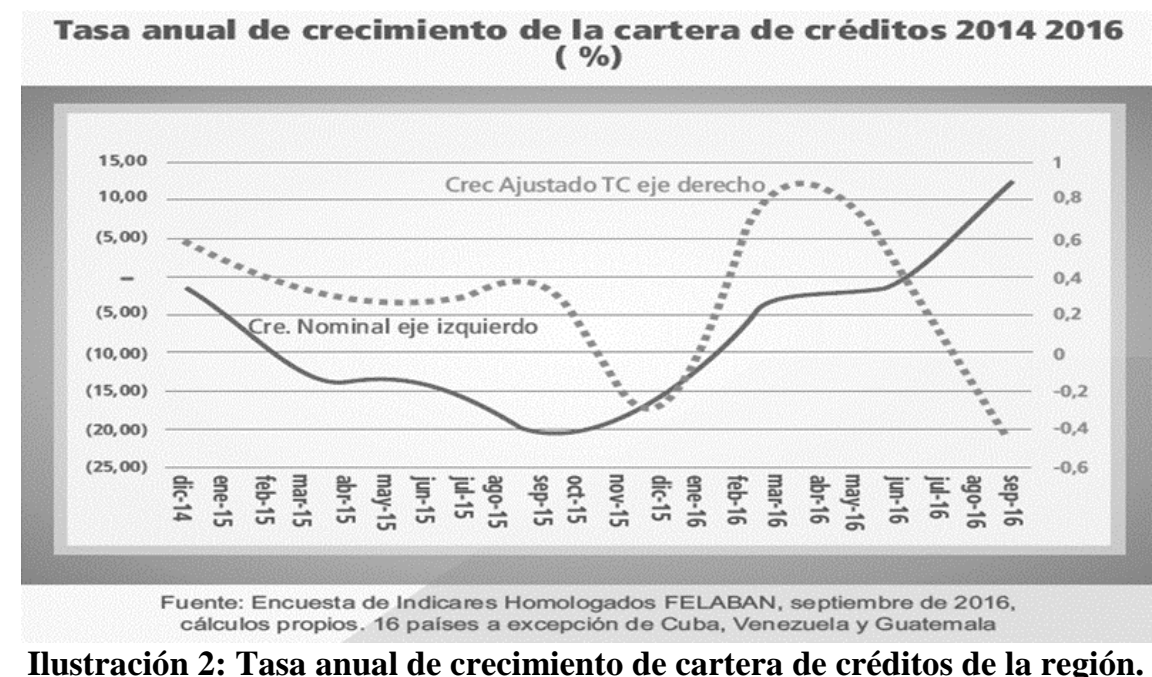

La economía de la región parece tener una mejor perspectiva en el año 2017. Después de 2 años de crecimiento negativo, para algunos observadores, el conjunto de la región puede afrontar un punto de inflexión en las tendencias de la economía. Varios factores pueden impulsar un mejor desempeño de la región, entre ellos, una menor inflación en países que se vieron afectados por brotes de alza de precios en el pasado reciente, un mejor desenvolvimiento de las variables del sector externo y una mejora de los términos de intercambio, mayor inversión privada, en especial en lo que se refiere a infraestructura. (Federación Lationamericana de Bancos, 2017) Lo más probable es que lo peor de la recesión de Brasil haya pasado, Argentina empieza a ver los frutos de un ajuste macroeconómico que ha incluido normalización del mercado cambiario y negociaciones sobre el default selectivo. Perú y Chile son países que tienen una mejor perspectiva de crecimiento y sus pronósticos incluso han sido revisados al alza.

Sin embargo, se advierte que la región todavía estará lejos de su potencial de crecimiento de largo plazo. Así las cosas, los pronósticos indican que la región podría crecer entre el 1.5\% y el $1.8 \%$. Indudablemente, la debilidad de los mercados laborales y el menor espacio fiscal que tienen los gobiernos centrales, son factores que significarán un lastre para las economías regionales. (Federación Lationamericana de Bancos, 2017). También se avizora que algunos países de la región afronten algunas dificultades fiscales, tal como es el caso de algunos países centroamericanos. En el marco de los recientes resultados electorales de Estados Unidos, resulta importante revisar el caso de México, principalmente por la postura proteccionista de Donald Trump, la que ha generado incertidumbre frente a los flujos futuros de comercio con debilitamiento del peso mexicano. Incluso el anuncio del presidente electo de retirar a los Estados Unidos del Tratado del Pacífico ha generado volatilidad en los mercados financieros, tanto latinoamericanos, como de buena parte de los mercados emergentes. 
A junio de 2016 el sistema bancario latinoamericano evidenció un menor crecimiento económico en la región. La cartera de créditos decreció un $-0.85 \%$ y el activo creció al $2.42 \%$ en total. El crecimiento del activo pudo estar asociado a que el sector bancario tiene una posición de inversionista en activos distintos a cartera, que está compuesta de títulos valores, tanto de carácter público como privado. (Ministerio de Finanzas, 2016)

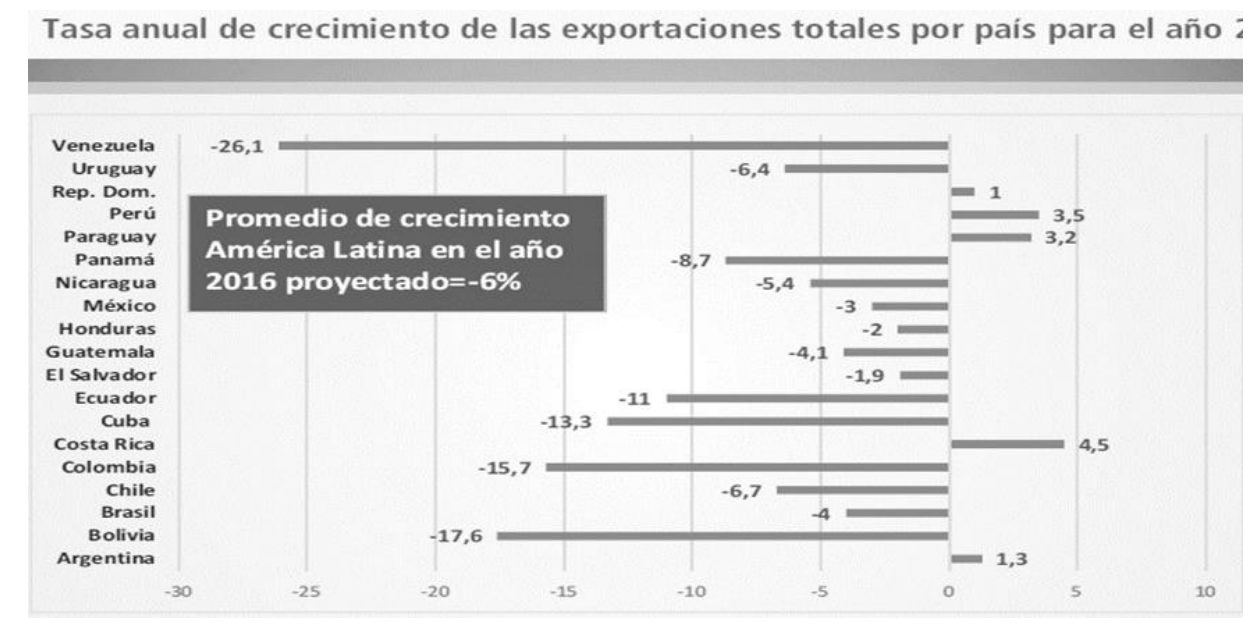

Ilustración 3: Tasa anual de crecimiento de las exportaciones de países de la región.

El principal servicio del sistema bancario es brindar confianza al público, es por ello que los fondos captados deben ser distribuidos eficientemente para apoyar actividades productivas. Por lo cual es indispensable la supervisión de la solidez y eficiencia de los intermediarios bancarios y además que las políticas de regulación deben incentivar un mayor abastecimiento del crédito. La evolución del crédito puede ser explicada por factores de la oferta de crédito o por factores de demanda.

\section{La economía ecuatoriana}

Durante el 2014, la economía ecuatoriana atravesó una fase de menor crecimiento, ligeramente superior a la actual, esto a raíz de un menor dinamismo de la demanda interna. Los ingresos estatales ya no aumentaron al ritmo que lo hacían en años previos, repercutiendo en menores tasas de expansión del gasto y la inversión pública, lo que también llevó a un enfriamiento del consumo privado. Entre 2010 y 2014, Ecuador había contado con precios de los commodities históricamente altos y una política monetaria expansiva por parte de la Reserva Federal, que había inundado de dólares a la economía mundial. Esto favoreció la competitividad de las exportaciones ecuatorianas y aseguró un flujo sostenido de dólares a la economía nacional, cuya liquidez sostuvo una fuerte expansión del gasto y la inversión pública, así como el dinamismo del consumo privado.

A lo que contribuyó la banca privada ecuatoriana, mediante la canalización de crédito a diversas actividades económicas. Así, entre diciembre de 2009 y diciembre de 2014, la cartera de crédito de la banca se duplicó, al pasar de los $\$ 9,454$ millones a los $\$ 19,652$ millones.

(Asociación de Bancos Privados del Ecuador). El Banco Central del Ecuador indica que en contraste con al positivo desempeño económico de principios del año anterior, la abrupta 
caída del precio del petróleo de valores de $\$ 100$ a mediados de 2014, hasta valores cercanos a los \$40 (WTI) en los últimos meses del 2015, ha llevado a hacer ajustes en los gastos y la inversión pública que el gobierno realizará en el presente año. Es posible que el gasto presupuestado se reduzca más de los US\$1.420 millones anunciados inicialmente por el Gobierno Nacional.

(Super Intendencia de Bancos y Seguros). Pero el mayor impacto está dado por un menor flujo de dólares al país, al representar el petróleo más de la mitad de las exportaciones ecuatorianas.

A esto se suma una fuerte apreciación del dólar en el mercado internacional, lo que también provoca una pérdida de competitividad de las exportaciones ecuatorianas frente a las de otros socios comerciales. Un bajo precio del petróleo y un dólar fuerte, son una combinación desfavorable para las cuentas externas del país y para las finanzas públicas. Desde 1973 el valor del dólar en términos de las monedas extranjeras cambia todos los días. En este entorno de tipos de cambio determinadas por el mercado, medir el valor internacional del dólar es una tarea confusa. (Carbaugh, 2009, pág. 382)

En esta coyuntura, el gobierno ha propuesto medidas comerciales que permitan reducir el monto de importaciones, para evitar la salida de dólares de la economía. Salvaguardias, cupos y restricciones técnicas al comercio que seguramente se profundizarán en el mediano plazo y que podrían estar acompañadas de otras medidas que reduzcan la salida de divisas del país por las fronteras tanto norte como sur, a esto se suma una activa búsqueda de financiamiento externo, no sólo para financiar el presupuesto gubernamental, sino también para que los dólares que dejan de fluir por concepto de exportaciones petroleras, sean compensados con esos recursos frescos.

Adicionalmente, el gobierno apuesta a los compromisos del gobierno chino y probablemente a una nueva colocación de bonos en los mercados internacionales. Las restricciones comerciales impactan sobremanera en el sector comercial por lo que el gobierno tuvo que revertir ciertas medidas tomadas, claramente con un tinte político para superar el bache, mención por la eliminación de salvaguardias para las llantas. En consecuencia la menor liquidez en la economía se traduce en un menor crecimiento de los depósitos en el sistema financiero, lo que lleva a la desaceleración del crédito. (Registro Oficial n³32).

El enfoque de la política monetaria orientado por el gobierno debe mantenerse debido al escudo protector que ha reducido el impacto económico de las importaciones de los países vecinos a precios más bajos debido a la apreciación del dólar y la devaluación de sus monedas, en consecuencia, es factible continuar con esta medida hasta que el mercado global tienda a estabilizarse. Un rubro importante de las fuentes de liquidez de las Otras Sociedades de Depósitos en julio de 2015, fue el incremento de los depósitos del sector privado en las OSD por USD 41.6 millones respecto de junio de 2015, lo que implicó que el saldo total de depósitos de las empresas y de los hogares sea de USD 28,914.1 millones, frente a USD 28,872.5 millones registrados en el mes anterior. (Asociación de Bancos Privados del Ecuador)

Del análisis de las captaciones por sector institucional, se observó que los depósitos de las empresas aumentaron en USD 121.7 millones frente a junio de 2015, y registraron una tasa de variación anual de -2.0\%; mientras que los depósitos de los hogares se redujeron en USD 80.1 
millones y presentaron una tasa de variación anual de 4.9\%. Por instrumento financiero, los depósitos a la vista fueron menores en USD 52.0 millones, y; los depósitos de ahorro y a plazo se incrementaron en USD 93.6 millones. Al realizar el análisis de la cartera por sector institucional, se observa que la cartera por vencer de las empresas se incrementó en USD 352.6 millones y registró una tasa de variación anual de 6.6\%. Por su parte, la cartera por vencer de los hogares se redujo en USD 2.2 millones frente a junio de 2015 y presentó una tasa anual de variación de 9.7\%. Por otro lado, la cartera vencida de las empresas aumentó en USD 2.2 millones, como la de los hogares que se incrementó en USD 21.6 millones.

\section{La banca privada y su aporte al sector productivo}

El desarrollo y desempeño del sector financiero nacional se evidencia en las cifras que cada mes publica la Superintendencia de Bancos, las cuales demuestran que el sistema se encuentra "saludable y sólido". Según la entidad, de enero a agosto la banca ecuatoriana reportó utilidades por $\$ 208,6$ millones, con un incremento del 2,15\% en relación al mismo período de 2014. Ya sea para capital de trabajo, compra de maquinaria o simplemente liquidez, el crédito bancario es una fuente importante de financiamiento para las empresas. Pero desde hace varias semanas la banca privada comenzó a restringir la entrega de préstamos.

(Madura, 2009) En su libro de Administración Financiera Internacional dice: La teoría de la paridad del poder de compra sugiere que los movimientos en el tipo de cambio los ocasionan los diferenciales en la tasa de inflación. Si las tasas de interés reales son las mismas en varios países, cualquier diferencia en las tasas de interés nominales podría atribuirse a la diferencia en la inflación esperada.

Los datos muestran que la banca está sólida y líquida, pero también que está tomando previsiones para preservar la liquidez en un año complicado. (Sebastián González \& López Pascual, 2014) El decrecimiento de los depósitos a la vista está haciendo que la banca sea más cautelosa a la hora de otorgar créditos. La restricción se refleja en mayores requisitos para los clientes, tiempos más largos en la aprobación y desembolsos, y la exigencia de más garantías. Los créditos entregados por la banca privada han sido de gran importancia para el dinamismo de la economía productiva en Ecuador. Desde 2010, el volumen de crédito se ha incrementado de manera progresiva y el año anterior no fue la excepción.

En 2014, existió un aumento considerable en la entrega de créditos hacia distintos sectores, es así que según los datos del Banco Central el volumen total de crédito fue US\$20.106 millones, entre créditos de consumo, vivienda, productivos, microcréditos, entre otros. En 2013 se entregaron US\$18.650 millones, es decir se registra un crecimiento de 7,8\% durante el último año. Según (Parkin \& Loría Díaz, 2013) al precio de equilibrio, la cantidad demandada es igual a la cantidad ofrecida. En un mercado de vivienda, cuando el alquiler está en el nivel de equilibrio, la cantidad de vivienda ofrecida es igual a la cantidad de vivienda demandada y no hay escases ni excedente de vivienda.

El direccionamiento del crédito, es un tema delicado que debe ser manejado con mucha prudencia, sería muy importante para asegurar el sano desarrollo de la cartera de crédito, se considere la experiencia, fortalezas, capacidades y orientación estratégica que tiene cada actor 
del sistema financiero. Además, en 2014 se otorgaron cerca de US\$16.384 millones en créditos al sector productivo. Este sector ha sido el que más se ha beneficiado desde el año 2010. Este crecimiento evidencia el compromiso de la banca privada con la producción ecuatoriana.

En 2014, el 81,5\% del volumen total de créditos correspondieron a créditos al sector productivo y microcréditos. Los receptores de estos créditos son en su mayoría el sector industrial, emprendimiento, corporativo, construcción, empresarial, entre otros. El impulso de la política monetaria actual debe ser direccionado a más frentes, el actual direccionamiento hacia el sector de la construcción está relacionado al volumen de trabajo que se proyecta en este sector, de acuerdo al nivel socioeconómico y prolongado se debería profundizar en la agroindustria y un encadenamiento de las cadenas de valor para la generación de renta y promover el consumo interno. (Super Intendencia de Bancos y Seguros, 2015)

\section{El Riesgo País y la inversión crediticia.}

Las últimas cifras de Riesgo País (EMBIG) muestran que Ecuador, al cierre de febrero de 2017, tuvo un riesgo país de 607 puntos. Es decir, una reducción de 3 puntos básicos en relación a enero de 2017. De igual manera, existió una reducción de 957 puntos frente a febrero del año pasado. Además, se ubicó por encima del promedio de América Latina que fue de 442 puntos. (Dans, 2012) Así, la relación entre el riesgo país de Ecuador y el promedio de la región que era 2,3 en febrero de 2016, se ubicó, en febrero de 2017 en 1,4 veces. Al cierre de febrero de 2017, Colombia, Perú, y Chile fueron los países con menor riesgo país de la región con 199, 152 y 132 puntos, respectivamente. Al 20 de febrero de 2017, el Riesgo País de Ecuador alcanzó los 605 puntos.

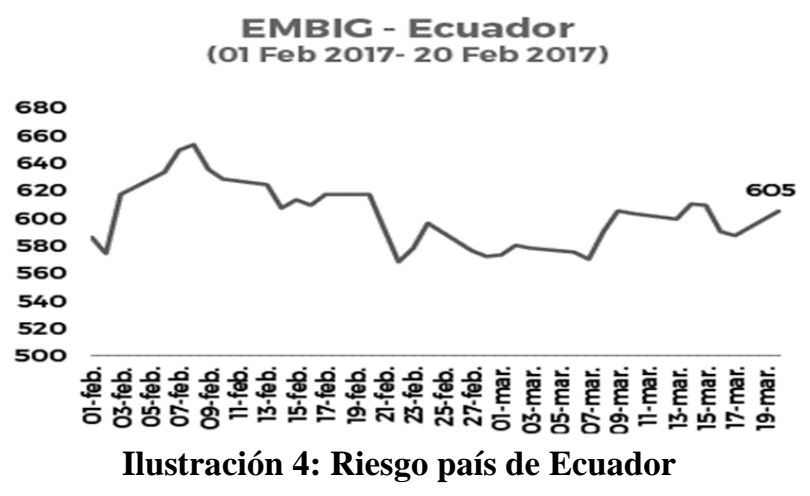

El desequilibrio que sufre el sistema económico nacional se debe principalmente a dos factores: la importante reducción del precio del barril de petróleo y el fortalecimiento del dólar. Para (Parkin \& Loría Díaz, 2013) el mercado de trabajo es el que determina nuestro empleo y nuestro salario. Las empresas deciden cuánto trabajo demandarán; cuanto más baja sea la tasa salarial, mayor será la cantidad de trabajo demandada.

El Régimen insiste en un modelo de desarrollo impulsado desde lo público, que es fácil de sostener en bonanza y es momento de analizar otra opción con más participación del sector privado e inversión privada. (Ministerio de Finanzas, 2016). El saldo de la balanza comercial es importante, porque es una de las principales fuentes de ingreso de divisas para el país junto con el petróleo, endeudamiento y remesas, que también están a la baja. Al cierre de febrero, la cartera 
bruta registró un saldo de USD 20.448 millones equivalente a un crecimiento mensual de $0,7 \%$. De manera anual, la cartera bruta creció en 10,6\%, lo que significó USD 1.966 millones más en créditos. Así, la tendencia de la cartera tras once meses de decrecimiento anual se detiene en octubre de 2016 y crece a partir de noviembre.

\begin{tabular}{|lcc|}
\hline \multicolumn{3}{|c|}{ Destino de la Cartera Bruta } \\
\hline Tipo de Crédito & Saldo & Composición \\
\hline Crédito Comercial & 10.184 & $50 \%$ \\
\hline Crédito a la Vivienda & 1.979 & $10 \%$ \\
\hline Crédito a la Microempresa & 1.500 & $7 \%$ \\
\hline Total Crédito a la Producción & 13.662 & $67 \%$ \\
\hline Crédito al Consumoy & 6.786 & $33 \%$ \\
\hline Educación & 20.448 & $100 \%$ \\
\hline Total Cartera Bruta & & C. \\
\hline
\end{tabular}

Ilustración 5: Destino de la cartera bruta

La propuesta del Régimen es sustituir la importación de bienes de consumo por producción nacional y el cambio de la matriz productiva, pero en la práctica el sector público sigue siendo el mayor inversionista y no avizora un despunte privado por las trabas y controles del Estado a la inversión. El gobierno después de aplicar según las palabras del Presidente Correa

"Crouding inn" durante los últimos años ha tomado la decisión de sentarse a dialogar con el sector privado con el fin de dinamizar la economía, buscando las alternativas que podrían derivar en un aporte más importante del sector privado en el aspecto socioeconómico, aun las actividades públicas son motor de crecimiento.

La altísima dependencia del gasto público como motor de la economía, la casi inexistente estrategia competitividad interna y externa, la inexistente estrategia de atracción de inversiones, el poquísimo encadenamiento interno de las compras públicas. (Comisión Económica para América Latina y el Caribe (CEPAL), 2015). El 2015 no es solamente un año difícil, sino que fácilmente puede referirse como un año de crisis. Tal como se presentó el primer tercio del año, se puede esperar una reducción importante de la tasa de crecimiento, respecto al año pasado, pero tampoco es catastrófico para la economía. Todo va a depender de qué tanto financiamiento logra conseguir el Gobierno para financiar el déficit.

\section{Situación crediticia privada del Ecuador}

En el mes de diciembre 2016, la cartera bruta para el subsistema de Bancos Privados ascendió a 20.375,06 millones de dólares, lo que representó una reducción del 8,5\% con relación a lo presentado en el mes de diciembre del 2015. Por el lado de la estructura de cartera, para el último mes del 2016 a la cartera comercial prioritario le correspondió el 45,79\% de participación, consumo prioritario el 29,16\%, Inmobiliario 9,64\%, Microempresa 7,75\%, Productivo 3,51\%, Educativo 2,11\%, Consumo Ordinario 1,54\%, Comercial ordinario 0,77\% y Vivienda de interés público el $0,11 \%$.

La relación cartera bruta - PIB para el período de análisis se incrementó de 18,70\% a 21,2\%. Por el lado de la cartera improductiva, esta representó el 3,90\% de la cartera total en 
diciembre del 2015 y 3,80\% en el mismo mes del 2016. Las provisiones a diciembre 2016 ascendieron a 1.366,47 millones. Por su parte la cartera productiva, en la cual se consideran las carteras: comercial y microcrédito, se incrementó en 13,5\%, de 10.208,96 millones a 11.584,17 millones de dólares. (Asociación de Bancos del Ecuador, 2017) La cartera problemática de estos sectores (cartera vencida más cartera que no devenga intereses) ascendió a 214,51 millones en diciembre 2016 lo cual representó un incremento del 13,8\% en el año de análisis. La cartera con calificaciones C, D y E de todos los segmentos de crédito pasó de 951,63 millones a 978,41 millones.

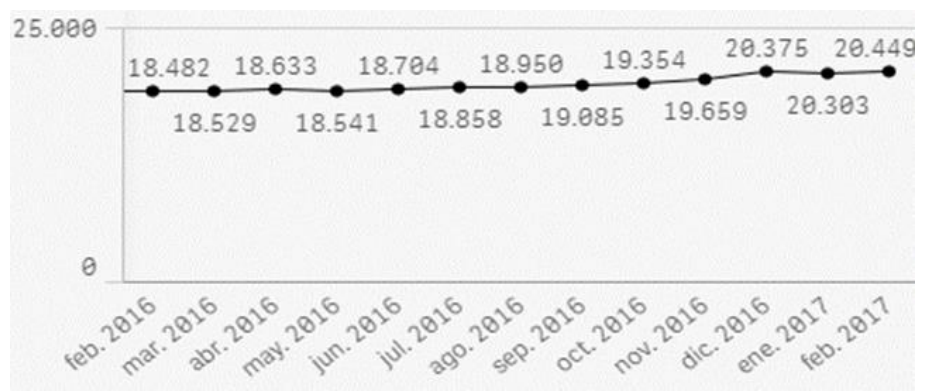

Ilustración 6: Créditos en el Ecuador

El sistema de Bancos atendió a un total de 24 sectores económicos en 2016, siendo los más relevantes a 2016: Consumo con una participación del 31,15\% del saldo de la cartera total (tarjeta de crédito con $16,80 \%$ y No productivo con 14,35\%), seguido por comercio al por mayor y menor con $15,58 \%$, industrias manufactureras con el $11,53 \%$, vivienda no productiva $9,66 \%$, entre las más importantes. Para el mes de Diciembre 2016 el sistema proporcionó recursos a 418 subsectores económicos, de éstos el que concentró la mayor parte del crédito fue consumo (consumo no productivo y consumo con tarjeta de crédito) con el 31,15\% de participación; seguido por vivienda no productiva 9,66\%; Otras actividades de concesión de créditos con 3,38\%; Actividades combinadas de servicios administrativos con 2,79\%; Venta de vehículos automotores $2,24 \%$; los demás subsectores poseen porcentajes de participación en la cartera menores al $2 \%$.

En este periodo, el sistema de Bancos financió 1.438 Actividades, de las cuales la principal actividad atendida fue consumo (tarjeta de crédito y consumo no productivo) con un aporte del $31,15 \%$, este tipo de crédito no posee un desglose que permita conocer para que se destinan los fondos concedidos, seguido por la vivienda no productiva con una participación del 9,66\% y Actividades de otorgamiento de crédito con una participación del 3,38\%, las demás actividades económicas participan en la cartera de los bancos con un porcentaje menor al $3 \%$.

\section{Análisis por tipo de crédito}

En el mes de diciembre 2016, la cartera bruta para el subsistema de Bancos Privados ascendió a 20.375,06 millones de dólares, lo que representó un crecimiento del 8,5\% con relación a lo presentado en el mes de diciembre 2015. Por el lado de la estructura de cartera, para diciembre 2016 a la cartera comercial prioritario le correspondió el 45,79\% de participación, consumo prioritario el 29,16\%, Inmobiliario 9,64\%, Microempresa 7,75\%, Productivo 3,51\%, Educativo 2,11\%, Consumo Ordinario 1,54\%, Comercial ordinario 0,77\% y Vivienda de interés público el 0,11\%. El gráfico 2.1.a muestra la composición de la cartera bruta en el período analizado y sus respectivos porcentajes de participación un año atrás. La relación cartera bruta PIB para el período de análisis se incrementó de 18,70\% a 21,2\%. Por el lado de la cartera 
improductiva, esta representó el 3,90\% de la cartera total en diciembre 2015 y 3,80\% en diciembre 2016. Las provisiones a diciembre 2016 ascendieron a 1.366,47 millones. Por su parte la cartera productiva, en la cual se consideran las carteras: comerciales y microcrédito, se incrementó en 13,5\%, de 10.208,96 millones a 11.584,17 millones de dólares. La cartera problemática de estos sectores (cartera vencida más cartera que no devenga intereses) ascendió a 214,51 millones en diciembre 2016 lo cual representó un incremento del 13,8\% en el año de análisis. En cuanto al monto promedio del crédito, en el mes de diciembre 2016 el tipo de crédito que tuvo un mayor incremento fue la cartera Productiva que pasó de 241.400,94 a 370.185,76 dólares de diciembre 2015 a diciembre 2016.

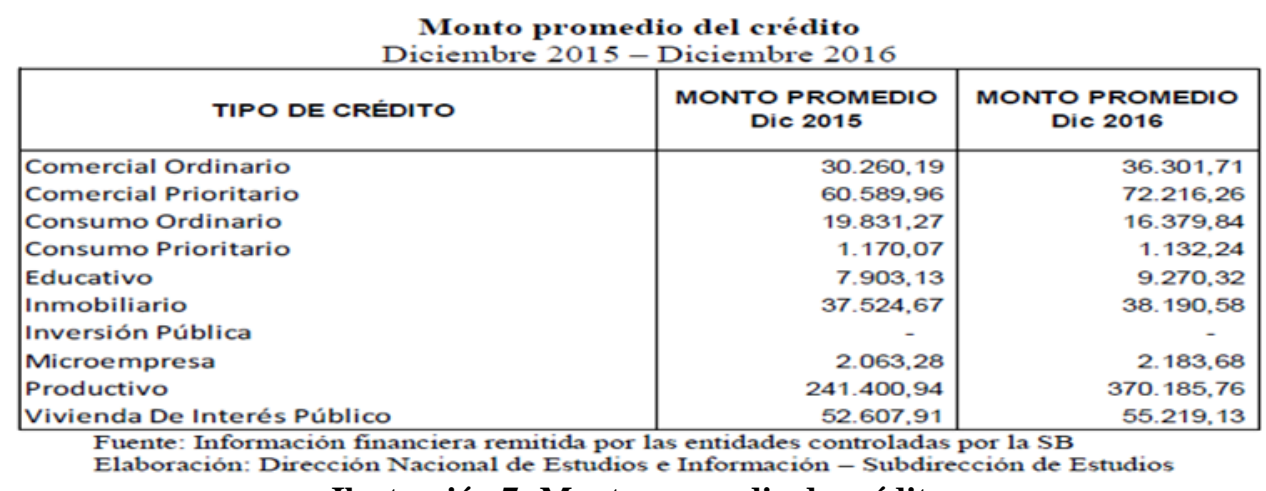

Ilustración 7: Monto promedio de crédito

\section{Análisis por subsector económico}

Para el mes de Diciembre 2016 el sistema proporcionó recursos a 418 subsectores económicos, de éstos el que concentró la mayor parte del crédito fue consumo (consumo no productivo y consumo con tarjeta de crédito) con el 31,15\% de participación; seguido por vivienda no productiva 9,66\%; Otras actividades de concesión de créditos con 3,38\%; Actividades combinadas de servicios administrativos con 2,79\%; Venta de vehículos automotores 2,24\%; los demás subsectores poseen porcentajes de participación en la cartera menores al 2\%. En el gráfico 2.3. a se puede observar otros subsectores representativos que forman parte de la cartera de bancos.

El titular de la Súper Intendencia de Bancos y Seguros asevera que no se está analizando en el corto plazo una reforma al tema de los segmentos de crédito o normas que tengan que ver con el tema. Lo que se está haciendo es una labor permanente de monitoreo de cómo va la liquidez, los montos de colocación y en general cómo se encuentra el sistema financiero. Una medida que reduce el impacto del impase actual es la canalización de créditos hacia el sector de la construcción y la reducción de la tasa de interés. Además del sector de la construcción, se podría incentivar también los sectores agroindustriales que han vuelto a entrar en la agenda del Gobierno, y en dónde la banca pública ha demostrado una ineficiencia persistente.

Eso puede generar un riesgo sistémico mayor al dirigir créditos y manejar tasas en forma política. La Junta redujo las tasas de interés promedio de los créditos para reactivar la actividad privada y reactivar el consumo. Dado que es difícil hacer política anti-cíclica, por el lado de mayor gasto público, el mecanismo de bajar la tasa de interés seguro estará en la agenda. De acuerdo a lo que señalan (Martín, Domínguez, Perea, Saca, \& Sánchez, 2011) las predicciones de 
los expertos, los factores ya enunciados y, particularmente la alta dependencia de la economía ecuatoriana del precio internacional del petróleo, provocarán una menor tasa de crecimiento de la misma respecto a las tasas de crecimiento registradas en años anteriores.

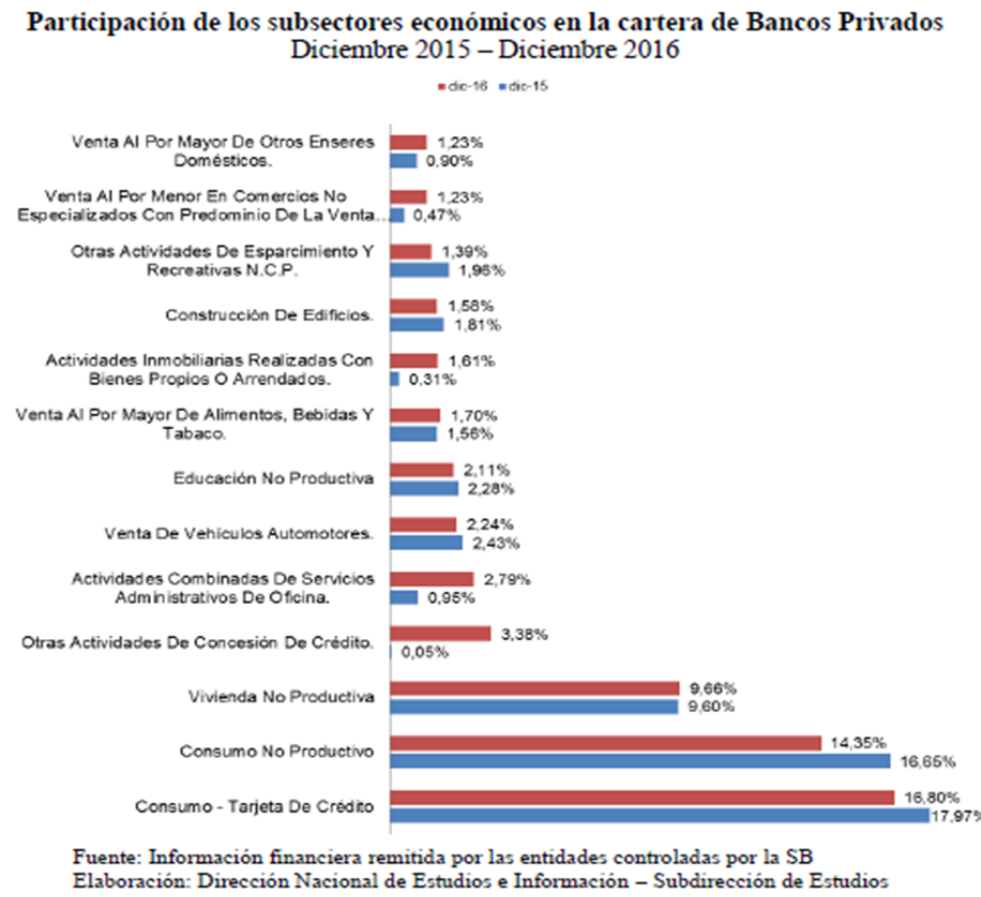

Ilustración 8: Participación de los subsectores económicos en la cartera de Bancos Privados.

En cuanto a la morosidad a nivel de subsector, el que presentó una mayor variación fue Actividades combinadas de servicios administrativos, que pasó de 0,35\% a 2,11\%, por lo tanto, tuvo un incremento de los 1,76 puntos porcentuales; vivienda no productiva presentó un incremento de 0,85 puntos, debido a que su morosidad a diciembre 2015 fue de $2,26 \%$ y en diciembre 2016 fue de 3,11\%; los demás subsectores poseen variaciones en el índice menores a 0,3 puntos porcentuales. (Asociación de Bancos del Ecuador, 2017), tomando en cuenta los subsectores principales que se expusieron en el gráfico 2.3.a se observa un incremento en la morosidad de 6 de ellos, y una reducción del índice en 7 subsectores, debido al cambio en el CIIU no existe un dato de morosidad para 4 subsectores en el mes de diciembre 2015, ya que estos fueron creados en la nueva clasificación.

\begin{tabular}{|c|c|c|c|}
\hline SUBSECTORES & $\begin{array}{c}\text { DICIEMBRE } \\
2015\end{array}$ & $\begin{array}{c}\text { DICIEMBRE } \\
2016\end{array}$ & VARIACIÓN P.P. \\
\hline Actividades Combinadas De Servicios Administrativo & $0,35 \%$ & $2,12 \%$ & 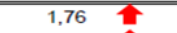 \\
\hline Vivienda No Productiva & $2,26 \%$ & $3,11 \%$ & 0,85 \\
\hline Venta Al Por Mayor De Otros Enseres Domésticos. & $0,73 \%$ & $0,96 \%$ & 0,23 \\
\hline Venta Al Por Menor En Comercios No Especializadc & $1,50 \%$ & $1,72 \%$ & 0,22 \\
\hline Actividades Inmobiliarias Realizadas Con Bienes Prc & $0,03 \%$ & $0,10 \%$ & 0,07 \\
\hline Consumo No Productivo & $6,88 \%$ & $6,93 \%$ & 0,04 \\
\hline Venta De Vehículos Automotores. & $1,44 \%$ & $1,44 \%$ & $(0,00)$ \\
\hline Otras Actividades De Concesión De Crédito. & $0,03 \%$ & $0,01 \%$ & $(0,03)$ \\
\hline Otras Actividades De Esparcimiento Y Recreativas $A$ & $1,35 \%$ & $1,04 \%$ & $(0,31)$ \\
\hline Educación No Productiva & $5,10 \%$ & $4,68 \%$ & $(0,42)$ \\
\hline Venta Al Por Mayor De Alimentos, Bebidas Y Tabac & $2,40 \%$ & $1,94 \%$ & $(0,46)$ \\
\hline Consumo - Tarjeta De Crédito & $6,99 \%$ & $6,40 \%$ & $(0,59)$ \\
\hline Construcción De Edificios. & $1,92 \%$ & $0,56 \%$ & $(1,36)$ \\
\hline TOTAL & $3,67 \%$ & $3,50 \%$ & $(0,17)$ \\
\hline
\end{tabular}

Ilustración 9: Morosidad por los subsectores económicos de mayor participación. 


\section{Análisis por destino geográfico del crédito - Provincia.}

Según información suministrada por (Asociación de Bancos del Ecuador, 2017), el destino geográfico hace referencia al lugar (provincia, cantón) donde se concedió el crédito y no necesariamente donde están siendo empleados los recursos. Existen dos provincias en las que se otorga principalmente el crédito, la provincia de Pichincha con 42,29\% y Guayas con 33,42\%, esto debido a que la mayor parte de instituciones financieras cuenta con su matriz en estas provincias, así como el mayor número de sucursales; les sigue la provincia de Azuay con 5,71\%, Manabí 3,74\%, El Oro 2,42\%, y Tungurahua 2,25\%, el resto de provincias cuenta con una participación en la cartera menor al $2 \%$, siendo las provincias de Napo y Galápagos en las que existe menos concesión de créditos: $0,08 \%$ y $0,02 \%$ respectivamente.

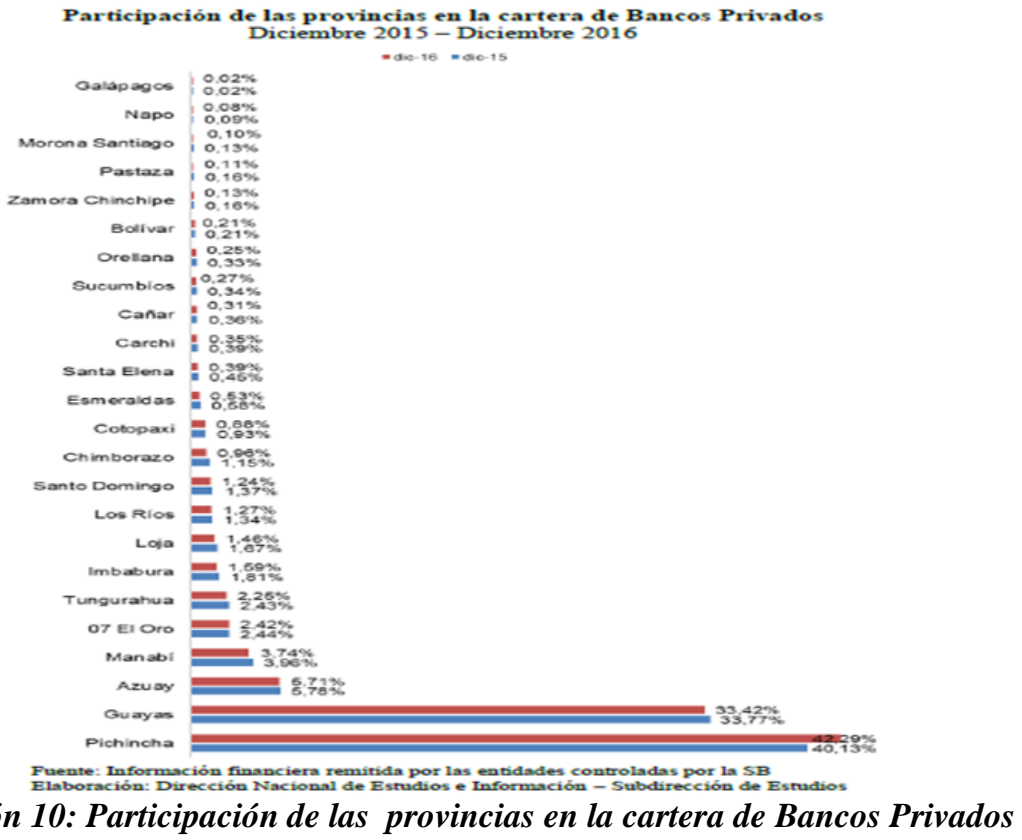

Ilustración 10: Participación de las provincias en la cartera de Bancos Privados

\section{Conclusiones}

La cartera bruta en el período diciembre 2015 - diciembre 2016 presentó un crecimiento del 8,50\%, alcanzando los 20.375,0 millones de dólares; el segmento comercial prioritario es el que representa la mayor parte del crédito otorgado 45,79\%, seguido por Consumo prioritario con el 29,16\%, Inmobiliario 9,64\%, Microempresa 7,37\%, Productivo 3,51\%, Educativo 2,28\%, Consumo Ordinario 1,54\%, Comercial ordinario 0,77\% y Vivienda de interés público el 0,11\%. El índice de morosidad en este período se redujo de 3,67\% a 3,5\% es decir 0,18 puntos porcentuales.

Se observa que los sectores a los que mayoritariamente otorgan créditos las instituciones bancarias son: Consumo con $31,15 \%$, seguido por comercio al por mayor y menor con $15,58 \%$, industrias manufactureras con el 11,53\% y vivienda no productiva con 9,66\%. Es decir, más del $67,92 \%$ de los créditos son captados por estos sectores económicos. Respecto a los niveles de morosidad, el sector consumo tarjeta de crédito presenta a diciembre 2016 un indicador de 6,40\% el más alto debido al riesgo implícito en este tipo de crédito. Además, al analizar la morosidad entre diciembre 2015 y 2016 se evidencia que, de los 24 sectores, 10 de ellos presentan mayor 
morosidad que lo reflejado en diciembre 2015, Actividades de hogares es el sector que más ha incrementado su indicador de mora $2,69 \%$.

Los factores de riesgo de la cartera además del índice de morosidad, constituidos la por cobertura y pérdidas esperadas ex post, presentaron diferentes comportamientos, de los 24 sectores 9 presentaron un decremento en el indicador de cobertura, y de la misma forma 7 sectores tuvieron un comportamiento desfavorable en el indicador de pérdidas esperadas ex post. Finalmente, las instituciones financieras deben poner especial atención en la colocación y gestión de recuperación de la cartera en las provincias del Oriente ecuatoriano como ya se había mencionado en los reportes anteriores, a esto se suma en el presente estudio la preocupación por el crecimiento en el índice de mora de la provincia de Carchi, que ha pasado de 4,89\% a 7,62\%.

Debido a problemas de iliquidez y de expectativas negativas de los agentes económicos por cuanto a la disminución de los precios del petróleo, apreciación del dólar, disminución del gasto público, reducción del dinamismo económico de China se prevé terminar el año con una recesión, esto es un crecimiento negativo del 1\% del PIB y por consiguiente la disminución de los depósitos y de los créditos.

Probablemente mediante la inversión extranjera directa y repatriación de capitales se podría disminuir los efectos de una inminente recesión.

La Junta de Política y Regulación Monetaria y Financiera redujo las tasas de interés con el fin de incentivar los créditos, pero no están dando los resultados esperados debido a la salida de la moneda por las fronteras. Actualmente el gobierno a través del BIESS le apuesta a los créditos hipotecarios de interés social pero no son suficientes, los créditos productivos se hallan estancados

\section{Bibliografía}

Asociación de Bancos del Ecuador. (2017). Boletín Macroeconómico. Quito: Asobanca. Recuperado el 25 de Marzo de 2017, de http://www.asobanca.org.ec/publicaciones/bolet\%C3\%ADnmacroecon\%C3\%B3mico/bolet\%C3\%ADn-macroecon\%C3\%B3mico-febrero-2017

Asociación de Bancos Privados del Ecuador. (2016). Boletín informativo. Guayaquil: Economía.

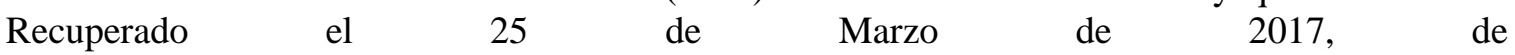
http://www.asobancos.org.ec/internas.asp?opcion=publicaciones.htm

Asociación de Bancos Privados del Ecuador. (s.f.). Boletín informativo $\mathrm{n}^{\circ}$ 50: La banca privada y su aporte al sector productivo. Obtenido de http://www.asobancos.org.ec/ABPE_INFORMA/50_2015.pdf

Asociación de Bancos Privados del Ecuador. (s.f.). Información Macroeconómica de Julio. Obtenido de http://www.asobancos.org.ec/inf_macro/Evoluci\%C3\%B3n_Julio\%202015.pdf

Carbaugh, R. (2009). Economía Internacional (Décima segunda ed.). México: Cengage Learning.

Comisión Económica para América Latina y el Caribe (CEPAL). (2015). Estudio Económico de América Latina y el Caribe. Santiago.

Dans, N. (2012). El riesgo país en la inversión extranjera directa: concepto y modalidades de riesgo. UCM, 109-129. Recuperado el 24 de Marzo de 2017, de http://revistas.ucm.es/index.php/PADE/article/view/41100 
Federación Lationamericana de Bancos. (2017). Informe trimestral económico bancario regional. Clec. Recuperado el 24 de Marzo de 2017, de http://www.felaban.net/publicaciones.php

Junta de Política y Regulación Monetaria y Financiera. (s.f.). Resolución N (033 - 040) -2015-G. Obtenido de http://www.bce.fin.ec/index.php/component/k2/item/707

Madura, J. (2009). Administración Financiera Internacional (Novena ed.). México: Cengage Learning.

Martín, M., Domínguez, J., Perea, J., Saca, F., \& Sánchez, S. (2011). La concentración bancaria y su impacto en los mercados de capitales de países emergentes. Anales de estudios económicos y empresariales, 159-177. Recuperado el 25 de Marzo de 2017, de https://www.bbvaresearch.com/wp-content/uploads/2014/09/WP-concentraci\%C3\%B3n-ycompetencia-sector-bancario.pdf

Ministerio de Finanzas. (2016). Presupuesto General del Estado. Obtenido de http://www.finanzas.gob.ec/wp-content/uploads/downloads/2014/11/Proforma-del-PGE-2015.pdf

Parkin, M., \& Loría Díaz, E. (2013). Microeconomía (Novena ed.). México: Pearson Education.

Presidencia de la República. (7 de Abril de 2015). Registro oficial No. 474: 622 Créese la Empresa Pública Nacional de Hábitat y Vivienda EP. Quito. Obtenido de https://www.registroficial.gob.ec/index.php/registro-oficial-web/publicaciones/registrooficial/item/1558-registro-oficial-no-474.html

Registro Oficial $\mathrm{n}^{\circ}$ 332. (s.f.). Código Orgánico Monetario y Financiero. Obtenido de http://www.asambleanacional.gob.ec/es/system/files/ro_codigo_organico_monetario_y_financier o.pdf

San Martín, N., \& Rodriguez, A. (2011). La imprevisibilidad de las crisis: un análisis empírico sobre los índices de riesgo. Innovar Journal, 21(39). Recuperado el 25 de Marzo de 2017, de http://www.scielo.org.co/scielo.php?script=sci_abstract\&pid=S0121$50512011000100013 \& \operatorname{lng}=\mathrm{es} \& n r m=$ is\&tlng=fr

Sebastián González, A., \& López Pascual, J. (2014). Economía y gestión bancaria. 268: Pirámide.

Súper Intendencia de Bancos y Seguros. (2015). Volúmen de Crédito del 2014. Obtenido de http://www.sbs.gob.ec/practg/sbs_index?vp_art_id=39\&vp_tip=2\&vp_buscr=41

Súper Intendencia de Bancos y Seguros. (s.f.). Volúmen de Crédito al 2015. Obtenido de http://www.sbs.gob.ec/practg/sbs_index?vp_art_id=39\&vp_tip=2\&vp_buscr=41 